\title{
Association between Angiopoietin-2 Gene Polymorphisms and Susceptibility to Coronary Artery Disease
}

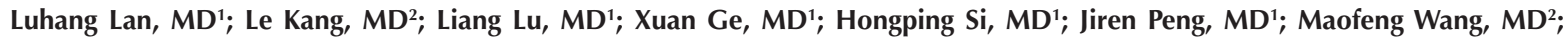 \\ Weimin Li, $\mathrm{MB}^{{ }^{*}}$; Chen-Ming Su, $\mathrm{PhD}^{3^{*}}$ \\ 'Department of Cardiology, Affiliated Dongyang Hospital of Wenzhou Medical University, Wuningxi Road 60, Dongyang, Zhejiang, \\ China \\ ${ }^{2}$ Department of Biomedical Sciences Laboratory, Affiliated Dongyang Hospital of Wenzhou Medical University, Wuningxi Road 60, \\ Dongyang, Zhejiang, China \\ ${ }^{3}$ Department of Sports Medicine, China Medical University, Taichung, Taiwan
}

\begin{abstract}
Background: Angiopoietin-2 (Angpt2) is associated with the progression of coronary artery disease (CAD). This research aimed to investigate the possible association between single nucleotide polymorphisms (SNPs) of ANGPT2 and CAD.

Methods: This research was performed in a hospital from the eastern region of China. From February 2019 to June 2019,222 patients with CAD were newly diagnosed and 403 healthy controls were confirmed by physical examinations. The distribution frequency of five SNPs of the ANGPT2 (rs11137037, rs2442598, rs12674822, rs1823375, and rs734701) in all participants was analyzed by real-time polymerase chain reaction (PCR) with SNP locus-specific probes.

Results: Our data showed that the participants with the TT genotype of rs2442598 were at reduced risk of CAD compared with wild-types (adjusted odds ratio $[\mathrm{AOR}]=0.511,95 \% \mathrm{Cl}: 0.283-0.923)$. The participants with the $\mathrm{AC}$ and $\mathrm{AC}+\mathrm{CC}$ genotypes of rs11137037 were at greater risk of CAD compared to wild-types (AOR $=1.754,95 \% \mathrm{Cl}: 1.140-2.699 ; \mathrm{AOR}=1.731,95 \% \mathrm{Cl}$ : 1.165-2.573, respectively). In addition, carriers of the GG+TT genotypes of rs12674822, showed more significant high-density lipoprotein than those of GG genotype, in addition, carriers of the GG+TT genotypes of rs12674822, showed more significant high-density lipoprotein than those of GG genotype ( $P=0.037)$.

Conclusion: These findings, as well as analysis of the haplotype, clearly indicate that ANGPT2 SNPs were highly correlated with susceptibility to CAD among the Han Chinese population.

Keywords: Angiopoietin-2, Coronary artery disease, Single nucleotide polymorphism

Cite this article as: Lan L, Kang L, Lu L, Ge X, Si H, Peng J, et al. Association between angiopoietin-2 gene polymorphisms and susceptibility to coronary artery disease. Arch Iran Med. 2021;24(8):622-628. doi: 10.34172/aim.2021.88
\end{abstract}

Received: September 7, 2020, Accepted: December 30, 2020, ePublished: August 1, 2021

\section{Introduction}

Coronary artery disease (CAD) is a common disorder in which coronary atherosclerosis leads to narrowing or occlusion of the coronary vascular lumen, resulting in myocardial ischemia, hypoxia, and even necrosis. ${ }^{1,2}$ With the improvement of living standards, the high mortality and morbidity resulting from CAD has attracted increased attention in China. ${ }^{3}$ Although CAD is related to blood lipids, hypertension, diabetes, lifestyle, obesity, and dietary habits, the genetic background is also a strong independent risk factor. ${ }^{4,5}$ The association between genetic variation and CAD has been demonstrated by numerous studies. ${ }^{6}$ Thus, identifying genetic factors is crucial for CAD, which can help us predict the occurrence and development of the disease earlier.

In clinical practice, in order to ensure adequate blood supply to the myocardium and prevent myocardial infarction, vascular recanalization has become the principal treatment regimen. ${ }^{7,8}$ As a self-compensating mechanism, angiogenesis can provide oxygen to the severely ischemic myocardium that is sufficient to improve prognosis. ${ }^{9,10}$ Compensatory angiogenesis has been found in various diseases of ischemia and hypoxia; therefore, angiogenesis may be helpful in the diagnosis and treatment of CAD. Angiopoietin-2 (Angpt2) is an important factor in angiogenesis. ${ }^{11}$ It functions by reducing vascular stability, promoting the activation of endothelial cells, and promoting the formation and remodeling of new blood vessels. ${ }^{2}$ Previous studies focused on Angpt 2 to identify the relationship between Angpt2 protein and CAD. Serum levels of Angpt2 were significantly increased among patients with CAD, which were significantly decreased after percutaneous coronary intervention, thereby showing the close correlation between serum levels of Angpt 2 and the severity of coronary artery stenosis. ${ }^{13}$ In another study, it was shown that the expression level of Angpt2 in serum of patients with CAD combined with heart failure was relatively high. ${ }^{14}$ Therefore, Angpt2 
is considered a biomarker of myocardial ischemia and vascular remodeling. We hypothesize that the Angpt2 genes are different in populations with $\mathrm{CAD}$, and that they might help us predict susceptibility to CAD in the CAD population.

Single nucleotide polymorphisms (SNPs) indicate the variation of a single nucleotide in the genome. ${ }^{15}$ ANGPT2 SNPs predict the prognosis of disease and the degree of risk for conditions, such as type 2 diabetes, neovascular age-related macular degeneration, polypoidal choroidal vasculopathies, acute lung injury and lung tumors, etc. ${ }^{16-}$ ${ }^{19}$ However, studies on the correlation between SNPs of ANGPT2 and CAD are limited in China. Therefore, in this study, we aimed to explore whether ANGPT2 SNPs are associated with the risk of CAD.

\section{Materials and Methods \\ Participants}

Participants were recruited from a tertiary hospital located in the central region of Zhejiang province, China. After excluding patients with tumors, kidney failure, autoimmune diseases, sepsis, and other diseases, ${ }^{20-23} 222$ patients diagnosed with $\mathrm{CAD}$ for the first time were recruited consecutively from February 2019 to June 2019. The criteria for the diagnosis of CAD were defined as coronary angiography with more than $50 \%$ stenosis. The control group consisted of 403 healthy volunteers who underwent physical examination in the same hospital. Healthy status was confirmed as no symptoms or abnormality in examinations indicating CAD or other diseases of the exclusion criteria mentioned above.

From all participants, clinical data were collected, including age, gender, tobacco, alcohol consumption, previous medical history, blood lipids related index, electrocardiogram (ECG), and cardiac function as proposed by the New York Heart Association. ${ }^{24}$

\section{Blood Sample Collection and DNA Extraction}

Prior to percutaneous coronary intervention, 3-5 mL venous blood was collected from each subject in a vacuum collector containing EDTA, then centrifuged to obtain blood cells. The DNA was harvested from the blood cells using a DNA extraction kit (Qiagen, Germany) and stored in TE buffer. ${ }^{19}$

\section{Angpt2 Polymorphisms}

Five ANGPT2 (OMIM accession number: 601922) SNPs (rs11137037, rs2442598, rs12674822, rs1823375, and rs734701) were selected and appropriate probes were designed as described previously. ${ }^{18,25,26}$

\section{Genotyping}

The polymerase chain reaction (PCR) reaction mix consisted of a volume of $10 \mu \mathrm{L}$, including genomic DNA, TaqMan Genotyping Master Mix (Applied Biosystems, USA), and probes. Details of amplification conditions, genotypes determination and data analysis are described in our previous study. ${ }^{19}$

\section{Statistical Analysis}

To analyze the data, the IBM SPSS Statistics v24.0 statistical software (Armonk, New York, USA) was used, and all measurement data were assumed to be normally distributed. Genotype distribution was tested using the Hardy-Weinberg Equilibrium law. Independent samples $t$ test (for quantitative data) and Fisher's exact test (for count data) were used to compare the data of controls with CAD patients. Odds ratios (OR) with 95\% confidence intervals (CIs) were calculated using multiple logistic regression models. Haplotype frequencies were analyzed by the Haploview software as described previously. ${ }^{27} P<$ 0.05 was considered statistically significant.

\section{Results}

We found the patients' mean age in the CAD group at $66.44 \pm 9.61$ years, and that of patients in the control group at $57.61 \pm 12.71$ years $(P<0.001$, Table 1$)$. The clinical data of the two groups were compared statistically. The frequencies of smoking history, drinking history, and the apolipoprotein A1/B ratio were significantly different $(P<0.01)$ between the two groups. Regarding ECG and heart failure status of patients in the CAD group, patients with changes in the ST segment of their ECG accounted for $36 \%$ of the patients in this group, and patients with the cardiac function of class III and IV accounted for $16.2 \%$.

A comparison of ANGPT2 genotypes in 403 healthy individuals and $222 \mathrm{CAD}$ patients is presented in Table 2. In both the CAD and the healthy control groups, the most common genotypes in rs2442598, rs734701, rs1823375, rs11137037, and rs12674822 were AT, TC, CC, AA, and GT, respectively. In rs2442598, individuals bearing the TT genotype were less likely to have CAD compared to patients with the AA genotype (adjusted odds ratio $[\mathrm{AOR}]=0.551 ; 95 \% \mathrm{CI}, 0.283-0.923 ; P<0.05$ ). In rs11137037, patients bearing the AC genotype were by 1.754-folds more likely to suffer from CAD compared to patients bearing the AA genotype (AOR $=1.754 ; 95 \% \mathrm{CI}$ 1.140-2.699; $P<0.05)$ and patients bearing $\mathrm{AC}+\mathrm{CC}$ were by 1.731 -folds more likely compared to patients bearing AA $($ AOR $=1.731 ; 95 \%$ CI 1.165-2.573; $P<0.05)$. These data indicated that $\mathrm{AC}$ and $\mathrm{AC}+\mathrm{CC}$ genotypes were more likely to be associated with CAD. No significant differences were observed in rs734701, rs1823375, rs12674822, and other genotypes when comparing CAD patients and healthy controls.

An independent samples t-test was employed to compare ANGPT2 SNPs with clinical data (Table 3), the GT+TT genotype of rs12674822 having a significance in high-density lipoprotein compared to the GG genotype in CAD patients $(P=0.037)$.

Table 4 shows that in rs734701, rs11137037, and rs12674822, patients with the T/C/G haplotype had a higher risk of CAD than patients bearing the T/A/T haplotype $(\mathrm{AOR}=1.574 ; 95 \% \mathrm{CI} 1.034-2.396 ; P<0.05)$, 
Table 1. Subjects' Characteristics

\begin{tabular}{|c|c|c|c|}
\hline Variable & $\begin{array}{c}\text { Controls } \\
n=403(\%)\end{array}$ & $\begin{array}{c}\text { Patients } \\
\mathrm{n}=222(\%)\end{array}$ & $P$ Value \\
\hline \multicolumn{4}{|l|}{ Gender } \\
\hline Female & $192(47.6)$ & $70(31.5)$ & \multirow{2}{*}{$<0.001$} \\
\hline Male & $211(52.4)$ & $152(68.5)$ & \\
\hline \multicolumn{4}{|l|}{ Smoking } \\
\hline No & $356(88.3)$ & $111(50.0)$ & \multirow[t]{2}{*}{$<0.001$} \\
\hline Yes & $47(11.7)$ & $111(50.0)$ & \\
\hline \multicolumn{4}{|l|}{ Alcohol } \\
\hline No & $339(84.1)$ & $119(53.6)$ & \multirow[t]{2}{*}{$<0.001$} \\
\hline Yes & $64(15.9)$ & $103(46.4)$ & \\
\hline \multicolumn{4}{|l|}{ NYHA classification } \\
\hline$I+I I$ & & $186(83.8)$ & \multirow[t]{2}{*}{-} \\
\hline III + IV & & $36(16.2)$ & \\
\hline \multicolumn{4}{|l|}{ ECG } \\
\hline Negative & & $142(64.0)$ & \multirow[t]{2}{*}{-} \\
\hline \multirow[t]{2}{*}{ Positive } & & $80(36.0)$ & \\
\hline & Mean \pm SD & Mean \pm SD & \\
\hline Age $(y)$ & $57.61 \pm 12.71$ & $66.44 \pm 9.61$ & $<0.001$ \\
\hline Triglyceride $(\mathrm{mmol} / \mathrm{L})$ & $1.573 \pm 1.032$ & $1.7254 \pm 1.123$ & 0.088 \\
\hline Total cholesterol (mmol/L) & $4.807 \pm 0.911$ & $3.957 \pm 1.100$ & $<0.001$ \\
\hline High-density lipoprotein (mmol/L) & $1.269 \pm 0.313$ & $1.077 \pm 0.274$ & $<0.001$ \\
\hline Low-density lipoprotein (mmol/L) & $2.762 \pm 0.825$ & $2.198 \pm 0.912$ & $<0.001$ \\
\hline Apolipoprotein A1/B & $1.594 \pm 0.599$ & $1.727 \pm 0.728$ & 0.023 \\
\hline
\end{tabular}

Statistical significance was analyzed by independent samples $t$ test or chi-square test. NYHA, New York heart association; ECG, Electrocardiogram; SD, Standard deviation.

while patients bearing the $\mathrm{T} / \mathrm{A} / \mathrm{G}$ haplotype were less likely to have CAD compared to patients with the T/A/T haplotype, suggesting it has a protective effect against the disease $(\mathrm{AOR}=0.187 ; 95 \% \mathrm{CI} 0.072-0.489 ; P<0.05)$.

\section{Discussion}

CAD has a complex pathology and no theory can fully explain the underlying mechanisms involved in its occurrence and development. Current clinical approaches, such as percutaneous transluminal coronary intervention, and thrombolytic and anticoagulant drugs are relatively mature and can effectively alleviate the patients' condition and reduce the risk of disease. ${ }^{28-30}$ Furthermore, angiogenesis may be a therapeutic approach for CAD when recanalization is not tolerated. ${ }^{31}$

Angpt2 is a member of a family of cytokines that can promote angiogenesis and includes Angpt1, Angpt2, Angpt3, Angpt4, and tyrosine kinase receptors 1 and 2 (tie-1, tie-2). ${ }^{20}$ In a previous study, it was shown that the expression of serum Angpt2 is higher in individuals with CAD, suggesting that Angpt 2 can be used as a potential clinical indicator for predicting $\mathrm{CAD}{ }^{32}$ In addition, Angpt2 appears to be related to myocardial blood flow reperfusion, indicating that it may play a role in the prognosis of CAD ${ }^{33,34}$ In a number of studies, it was shown that Angpt 2 indirectly participates in the regulation of inflammation by inducing sensitivity to TNF-alpha, thereby promoting the adhesion of endothelial cells. ${ }^{35}$ It is well known that inflammation is a cause of CAD. ${ }^{11}$ In addition, Qin et $\mathrm{al}^{36}$ found a key role for Angpt1 and Angpt2 in the development and maintenance of collateral coronary vessels in patients with severe CAD. Considering that CAD is a disease which is closely related to angiogenesis, it is feasible to predict the relationship between ANGPT2 polymorphisms and the risk of CAD.

In this study, we explored the relationship between ANGPT2 SNPs and CAD. Our candidate SNPs were found to be significantly correlated with diseases related to angiogenesis. ${ }^{18,25}$ So far, few studies have been performed to determine whether the five SNPs are associated with $\mathrm{CAD}$ in the Han Chinese population. In patients, the TT genotype in rs 2442598 is protective against CAD. In previous studies, rs 2442598 has demonstrated a significant correlation with psoriasis, ${ }^{37}$ and a correlation between psoriasis and myocardial ischemia was also observed. ${ }^{38} \mathrm{In}$ this study, we found that rs2442598 was correlated with CAD. In rs11137037, compared with subjects bearing the wild-type (AA), the AC and AC+CC genotypes were positively correlated with CAD. Interestingly, statistical differences were observed between different genotypes of rs12674822 in the high-density lipoprotein. Moreover, in previous studies, it was shown that the ApoA1/ApoB ratio 
Table 2. Angpt2 Genotype Frequencies in CAD Patients and Controls

\begin{tabular}{|c|c|c|c|c|}
\hline Variable & $\begin{array}{c}\text { Controls } \\
\mathrm{n}=403(\%)\end{array}$ & $\begin{array}{c}\text { Patients } \\
\mathrm{n}=222(\%)\end{array}$ & $\begin{array}{c}\text { OR } \\
(95 \% \mathrm{Cl})\end{array}$ & $\begin{array}{c}\text { AOR } \\
(95 \% \mathrm{Cl})\end{array}$ \\
\hline \multicolumn{5}{|c|}{ rs2442598 } \\
\hline AA & $96(23.8)$ & $59(26.6)$ & 1.00 (reference) & 1.00 (reference) \\
\hline AT & $214(53.1)$ & $123(55.4)$ & $0.935(0.631-1.385)$ & $0.837(0.529-1.324)$ \\
\hline TT & $93(23.1)$ & $40(18.0)$ & $0.700(0.428-1.145)$ & $0.511(0.283-0.923)^{*}$ \\
\hline $\mathrm{AT}+\mathrm{TT}$ & $307(76.2)$ & $163(73.4)$ & $0.864(0.593-1.258)$ & $0.731(0.471-1.135)$ \\
\hline \multicolumn{5}{|l|}{ rs734701 } \\
\hline TT & $142(35.2)$ & $78(35.1)$ & 1.00 (reference) & 1.00 (reference) \\
\hline TC & $183(45.4)$ & $89(40.1)$ & $0.885(0.609-1.288)$ & $1.004(0.646-1.563)$ \\
\hline $\mathrm{CC}$ & $78(19.4)$ & $55(24.8)$ & $1.284(0.825-1.997)$ & $1.229(0.720-2.098)$ \\
\hline $\mathrm{TC}+\mathrm{CC}$ & $261(64.8)$ & $144(64.9)$ & $1.004(0.713-1.415)$ & $1.078(0.716-1.621)$ \\
\hline \multicolumn{5}{|c|}{ rs1823375 } \\
\hline $\mathrm{CC}$ & $205(50.9)$ & $107(48.2)$ & 1.00 (reference) & 1.00 (reference) \\
\hline CG & $161(40.0)$ & $95(42.8)$ & $1.130(0.801-1.596)$ & $0.977(0.644-1.483)$ \\
\hline GG & $37(9.1)$ & $20(9.0)$ & $1.036(0.573-1.872)$ & $1.248(0.650-2.399)$ \\
\hline $\mathrm{CG}+\mathrm{GG}$ & $198(49.1)$ & $115(51.8)$ & $1.113(0.802-1.544)$ & $1.039(0.705-1.531)$ \\
\hline \multicolumn{5}{|c|}{ rs11137037 } \\
\hline $\mathrm{AA}$ & $201(49.4)$ & $91(41.0)$ & 1.00 (reference) & 1.00 (reference) \\
\hline $\mathrm{AC}$ & $143(35.5)$ & $89(40.1)$ & $1.375(0.957-1.975)$ & $1.754(1.140-2.699)^{*}$ \\
\hline $\mathrm{CC}$ & $59(14.6)$ & $42(18.9)$ & $1.572(0.986-2.508)$ & $1.719(0.956-3.093)$ \\
\hline $\mathrm{AC}+\mathrm{CC}$ & $202(50.1)$ & $131(59.0)$ & $1.432(1.029-1.995)^{*}$ & $1.731(1.165-2.573)^{*}$ \\
\hline \multicolumn{5}{|c|}{ rs12674822 } \\
\hline GG & $117(29.0)$ & $65(29.3)$ & 1.00 (reference) & 1.00 (reference) \\
\hline GT & 177 (43.9) & $105(47.3)$ & $1.068(0.725-1.573)$ & $1.366(0.862-2.166)$ \\
\hline TT & $109(27.1)$ & $52(23.4)$ & $0.859(0.548-1.345)$ & $0.843(0.489-1.454)$ \\
\hline $\mathrm{GT}+\mathrm{TT}$ & $286(71.0)$ & $157(70.7)$ & $0.988(0.689-1.417)$ & $1.167(0.755-1.803)$ \\
\hline
\end{tabular}

The odds ratios (ORs) with their 95\% confidence intervals (Cls) were estimated by multiple logistic regression models, and adjusted for age. $* P<0.05$.

Table 3. Clinical Parameters of CAD Patients with Different Genotypes at rs 12674822

\begin{tabular}{|c|c|c|c|}
\hline \multirow{2}{*}{ Parameter } & GG $(n=65)$ & $\mathrm{GT}+\mathrm{TT}(\mathrm{n}=157)$ & \multirow{2}{*}{$P$ Value } \\
\hline & Mean \pm SEM & Mean \pm SEM & \\
\hline Triglyceride $(\mathrm{mmol} / \mathrm{L})$ & $1.71 \pm 1.01$ & $1.73 \pm 1.17$ & 0.865 \\
\hline Total cholesterol (mmol/L) & $3.88 \pm 1.07$ & $3.99 \pm 1.11$ & 0.480 \\
\hline High-density lipoprotein (mmol/L) & $1.02 \pm 0.24$ & $1.10 \pm 0.28$ & $0.037^{*}$ \\
\hline Low-density lipoprotein (mmol/L) & $2.18 \pm 0.91$ & $2.21 \pm 0.91$ & 0.798 \\
\hline Apolipoprotein A1/ B & $1.61 \pm 0.60$ & $1.78 \pm 0.77$ & 0.097 \\
\hline
\end{tabular}

Statistical significance was analyzed by independent samples t-test between clinical parameters and the ANGPT2 rs12674822 polymorphisms.

negatively correlated with CAD, while ApoB positively correlated with CAD. ${ }^{39}$ In clinical studies, ApoA1, ApoB, and ApoA1/ApoB have been shown to be closely correlated with ST-segment elevation in the myocardium, thereby providing a basis for diagnosis of disease through which we believe that rs12674822 may be correlated with the risk of CAD. ${ }^{40}$ In addition, based on haplotype analysis, we found that individuals bearing the T/C/G haplotype in rs734701, rs11137037, and rs12674822 had a higher risk of CAD, while carriers of the T/A/G haplotype had a lower risk. Thus, haplotype analysis has helped us improve our ability to predict the risk of the disease. ${ }^{41}$

Angpt 2 has been analyzed in a number of diseases. Some studies have shown that the $1233 \mathrm{~A} / \mathrm{G}$ locus of ANGPT2 was associated with type 2 diabetes. ${ }^{16}$ There are four SNPs in ANGPT2 that may be related to neovascularization in retinal diseases. ${ }^{17}$ Studies on various ANGPT2 SNPs demonstrated that Angpt2 significantly correlated with the risk of diseases related to angiogenesis. In a previous report, it was shown that increased levels of Angpt2 were associated with hypertension and diabetes. ${ }^{42}$ Moreover, in obese individuals, serum levels of Angpt2 are higher 
Table 4. Distribution Frequency of ANGPT2 Haplotypes in Patients with CAD and Controls

\begin{tabular}{|c|c|c|c|c|c|c|}
\hline \multicolumn{3}{|c|}{ Haplotype Block } & \multirow{2}{*}{$\begin{array}{c}\text { Control } \\
\mathbf{n}=806(\%)\end{array}$} & \multirow{2}{*}{$\begin{array}{c}\text { Patients } \\
\mathrm{n}=444(\%)\end{array}$} & \multirow{2}{*}{$\begin{array}{c}\text { OR } \\
(95 \% \mathrm{Cl})\end{array}$} & \multirow{2}{*}{$\begin{array}{c}\text { AOR } \\
(95 \% \mathrm{Cl})\end{array}$} \\
\hline $\begin{array}{l}\text { rs734701 } \\
\text { T/C }\end{array}$ & $\begin{array}{c}\text { rs11137037 } \\
\text { A/C }\end{array}$ & $\begin{array}{c}\text { rs12674822 } \\
\text { G/T }\end{array}$ & & & & \\
\hline $\mathrm{T}$ & A & $\mathrm{T}$ & 273 (33.9) & $148(33.3)$ & Reference & Reference \\
\hline C & A & G & $187(23.2)$ & $108(24.3)$ & $1.065(0.781-1.453)$ & $1.116(0.803-1.551)$ \\
\hline C & $\mathrm{C}$ & G & $95(11.7)$ & $62(14.0)$ & $1.204(0.825-1.756)$ & $1.364(0.911-2.041)$ \\
\hline $\mathrm{T}$ & $\mathrm{C}$ & G & $77(9.5)$ & $60(13.5)$ & $1.437(0.971-2.128)$ & $1.574(1.034-2.396)^{*}$ \\
\hline $\mathrm{T}$ & $\mathrm{C}$ & $\mathrm{T}$ & $65(8.1)$ & $32(7.2)$ & $0.908(0.569-1.450)$ & $0.946(0.578-1.549)$ \\
\hline $\mathrm{T}$ & A & G & $52(6.5)$ & $5(1.1)$ & $0.177(0.069-0.454)$ & $0.187(0.072-0.489)^{*}$ \\
\hline C & $\mathrm{C}$ & $\mathrm{T}$ & $24(3.0)$ & $19(4.3)$ & $1.460(0.774-2.754)$ & $1.703(0.863-3.362)$ \\
\hline C & $A$ & $\mathrm{~T}$ & $33(4.1)$ & $10(2.3)$ & $0.559(0.268-1.166)$ & $0.521(0.241-1.124)$ \\
\hline
\end{tabular}

The odds ratios (ORs) with their 95\% confidence intervals $(\mathrm{Cls})$ were estimated by multiple logistic regression models, and adjusted for smoking, alcohol consumption, and age. $* P<0.05$

compared to healthy controls. ${ }^{43}$ It is well known that hypertension, diabetes, and obesity are risk factors of $\mathrm{CAD}$, indicating that there may be an indirect effect for Angpt 2 on the incidence of CAD. Therefore, further studies should be conducted that focus on investigating the underlying mechanism of the angiogenesis process in the pathogenesis of CAD.

A limitation of this study is that CAD is caused by multiple genes and factors, and not by a single gene locus. Moreover, the results of SNP analysis are limited by the number of samples available. The reliability of the experimental results can be improved by increasing the sample size, expanding the sample collection range, and exploring a greater number of Angpt2 gene loci to further provide evidence of angiogenesis in the treatment of CAD.

In conclusion, our findings demonstrated that ANGPT2 SNPs are possibly associated with susceptibility to CAD. By analyzing polymorphisms of ANGPT2 in the population at risk for $\mathrm{CAD}$, we may be able to predict the occurrence of disease and provide interventions. The involvement of ANGPT2 SNPs in the function of CAD remains unclear; therefore, further studies are warranted to investigate the underlying mechanism.

\section{Conflict of Interest Disclosures}

The authors declare that they have no conflict of interest.

\section{Ethical Statement}

This study's protocol was approved by the Ethics Committee of Dongyang People's Hospital and all experiments were performed in accordance with relevant guidelines and regulations. Written informed consent was obtained from all participants before study entry. Written consent was provided by the participants and this study was approved by the Ethics Committee and Institutional Review Board of Dongyang People's Hospital (2019-YX-21).

\section{Funding}

Statistics for this manuscript were supported by the Department of Biotechnology, Asia University (Taichung, Taiwan). This work was supported by grants from the China Medical University (CMU109-N-06 and CMU109-MF-112).

\section{Authors' Contribution}

LL, CmS and WL designed the study and wrote the manuscript. LK, LL, MW and CmS performed the statistical analysis. LL, XG, HS and JP collected the data. The manuscript was approved by all authors.

\section{References}

1. Yao HC, Zhou M, Zhou YH, Wang LH, Zhang DY, Han QF, et al. Intravenous high mobility group box 1 upregulates the expression of HIF-1 $\alpha$ in the myocardium via a protein kinase B-dependent pathway in rats following acute myocardial ischemia. Mol Med Rep. 2016;13(2):1211-9. doi: $10.3892 / \mathrm{mmr} .2015 .4648$.

2. Hay SI, Abajobir AA, Abate KH, Abbafati C, Abbas $\mathrm{KM}$, Abd-Allah F, et al. Global, regional, and national disability-adjusted life-years (DALYs) for 333 diseases and injuries and healthy life expectancy (HALE) for 195 countries and territories, 1990-2016: a systematic analysis for the Global Burden of Disease Study 2016. Lancet. 2017;390(10100):1260-344. doi: 10.1016/s01406736(17)32130-x.

3. Zhou M, Wang H, Zhu J, Chen W, Wang L, Liu S, et al. Causespecific mortality for 240 causes in China during 1990-2013: a systematic subnational analysis for the Global Burden of Disease Study 2013. Lancet. 2016;387(10015):251-72. doi: 10.1016/s0140-6736(15)00551-6.

4. Chow CK, Jolly S, Rao-Melacini P, Fox KA, Anand SS, Yusuf S. Association of diet, exercise, and smoking modification with risk of early cardiovascular events after acute coronary syndromes. Circulation. 2010;121(6):750-8. doi: 10.1161/ circulationaha.109.891523.

5. Knowles JW, Ashley EA. Cardiovascular disease: the rise of the genetic risk score. PLoS Med. 2018;15(3):e1002546. doi: 10.1371/journal.pmed.1002546.

6. Lu X, Wang L, Chen S, He L, Yang X, Shi Y, et al. Genomewide association study in Han Chinese identifies four new susceptibility loci for coronary artery disease. Nat Genet. 2012;44(8):890-4. doi: 10.1038/ng.2337.

7. Thiele H, Akin I, Sandri M, Fuernau G, de Waha S, Meyer-Saraei R, et al. PCI strategies in patients with acute myocardial infarction and cardiogenic shock. N Engl J Med. 2017;377(25):2419-32. doi: 10.1056/NEJMoa1710261.

8. Gu D, Qu J, Zhang H, Zheng Z. Revascularization for coronary artery disease: principle and challenges. Adv Exp 
Med Biol. 2020;1177:75-100. doi: 10.1007/978-981-152517-9_3.

9. Regieli JJ, Jukema JW, Nathoe HM, Zwinderman AH, Ng S, Grobbee DE, et al. Coronary collaterals improve prognosis in patients with ischemic heart disease. Int J Cardiol. 2009;132(2):257-62. doi: 10.1016/j.ijcard.2007.11.100.

10. Mitsuma W, Kodama M, Hirono S, Ito M, Ramadan MM, Tanaka K, et al. Angiopoietin-1, angiopoietin-2 and tie-2 in the coronary circulation of patients with and without coronary collateral vessels. Circ J. 2007;71(3):343-7. doi: 10.1253/circj.71.343.

11. Scholz A, Plate KH, Reiss Y. Angiopoietin-2: a multifaceted cytokine that functions in both angiogenesis and inflammation. Ann N Y Acad Sci. 2015;1347:45-51. doi: 10.1111/nyas. 12726.

12. Parikh SM. The angiopoietin-Tie2 signaling axis in systemic inflammation. J Am Soc Nephrol. 2017;28(7):1973-82. doi: 10.1681/asn.2017010069.

13. Zeng ZY, Gui C, Li L, Wei XM. Effects of percutaneous coronary intervention on serum angiopoietin-2 in patients with coronary heart disease. Chin Med J (Engl). 2016;129(6):631-5. doi: 10.4103/0366-6999.177968.

14. Varricchi G, Loffredo S, Bencivenga L, Ferrara AL, Gambino G, Ferrara N, et al. Angiopoietins, vascular endothelial growth factors and secretory phospholipase A2 in ischemic and non-ischemic heart failure. J Clin Med. 2020;9(6):1928. doi: $10.3390 / \mathrm{jcm} 9061928$.

15. Robert F, Pelletier J. Exploring the impact of singlenucleotide polymorphisms on translation. Front Genet. 2018;9:507. doi: 10.3389/fgene.2018.00507.

16. He Q, Luo HM, Zhu BS, Tang XH, Jiang LZ. [Association of $1233 \mathrm{~A} / \mathrm{G}$ polymorphism of angiopoietin-2 gene with type 2 diabetes mellitus and diabetic nephropathy]. Zhonghua Yi Xue Yi Chuan Xue Za Zhi. 2012;29(1):72-6. doi: 10.3760/ cma.j.issn.1003-9406.2012.01.018. [Chinese].

17. Ma L, Brelen ME, Tsujikawa M, Chen H, Chu WK, Lai TY, et al. Identification of ANGPT2 as a new gene for neovascular age-related macular degeneration and polypoidal choroidal vasculopathy in the Chinese and Japanese populations. Invest Ophthalmol Vis Sci. 2017;58(2):1076-83. doi: 10.1167/iovs.16-20575.

18. Meyer NJ, Li M, Feng R, Bradfield J, Gallop R, Bellamy $\mathrm{S}$, et al. ANGPT2 genetic variant is associated with trauma-associated acute lung injury and altered plasma angiopoietin-2 isoform ratio. Am J Respir Crit Care Med. 2011;183(10):1344-53. doi: 10.1164/rccm.201005-0701OC.

19. Hu W, Tang CH, Chen HT, Zhao J, Jin L, Kang L, et al. Correlations between angiopoietin-2 gene polymorphisms and lung cancer progression in a Chinese Han population. J Cancer. 2019;10(13):2935-41. doi: 10.7150/jca.31134.

20. Scholz A, Plate KH, Reiss Y. Angiopoietin-2: a multifaceted cytokine that functions in both angiogenesis and inflammation. Ann N Y Acad Sci. 2015;1347:45-51. doi: 10.1111/nyas. 12726.

21. Wilson PW, D’Agostino RB, Levy D, Belanger AM, Silbershatz H, Kannel WB. Prediction of coronary heart disease using risk factor categories. Circulation. 1998;97(18):1837-47. doi: 10.1161/01.cir.97.18.1837.

22. Beck H, Acker T, Wiessner C, Allegrini PR, Plate KH. Expression of angiopoietin-1, angiopoietin-2, and tie receptors after middle cerebral artery occlusion in the rat. Am J Pathol. 2000;157(5):1473-83. doi: 10.1016/s0002-
9440(10)64786-4

23. Padberg JS, Wiesinger A, di Marco GS, Reuter S, Grabner A, Kentrup D, et al. Damage of the endothelial glycocalyx in chronic kidney disease. Atherosclerosis. 2014;234(2):33543. doi: 10.1016/j.atherosclerosis.2014.03.016.

24. Chioncel O, Lainscak M, Seferovic PM, Anker SD, CrespoLeiro MG, Harjola VP, et al. Epidemiology and oneyear outcomes in patients with chronic heart failure and preserved, mid-range and reduced ejection fraction: an analysis of the ESC Heart Failure Long-Term Registry. Eur J Heart Fail. 2017;19(12):1574-85. doi: 10.1002/ejhf.813.

25. Miaskowski C, Dodd M, Paul SM, West C, Hamolsky D, Abrams G, et al. Lymphatic and angiogenic candidate genes predict the development of secondary lymphedema following breast cancer surgery. PLoS One. 2013;8(4):e60164. doi: 10.1371/journal.pone.0060164.

26. Dai C, Kuo SJ, Zhao J, Jin L, Kang L, Wang L, et al. Correlation between genetic polymorphism of angiopoietin-2 gene and clinical aspects of rheumatoid arthritis. Int J Med Sci. 2019;16(2):331-6. doi: 10.7150/ijms.30582.

27. Barrett JC, Fry B, Maller J, Daly MJ. Haploview: analysis and visualization of $\mathrm{LD}$ and haplotype maps. Bioinformatics. 2005;21(2):263-5. doi: 10.1093/bioinformatics/bth457.

28. Armstrong PW, Gershlick AH, Goldstein P, Wilcox R, Danays T, Lambert Y, et al. Fibrinolysis or primary PCI in ST-segment elevation myocardial infarction. N Engl J Med. 2013;368(15):1379-87. doi: 10.1056/NEJMoa1301092.

29. Cantor WJ, Fitchett D, Borgundvaag B, Ducas J, Heffernan $\mathrm{M}$, Cohen EA, et al. Routine early angioplasty after fibrinolysis for acute myocardial infarction. N Engl J Med. 2009;360(26):2705-18. doi: 10.1056/NEJMoa0808276.

30. O'Gara PT, Kushner FG, Ascheim DD, Casey DE Jr, Chung MK, de Lemos JA, et al. 2013 ACCF/AHA guideline for the management of ST-elevation myocardial infarction: executive summary: a report of the American College of Cardiology Foundation/American Heart Association Task Force on Practice Guidelines. J Am Coll Cardiol. 2013;61(4):485-510. doi: 10.1016/j.jacc.2012.11.018.

31. Khan TA, Sellke FW, Laham RJ. Gene therapy progress and prospects: therapeutic angiogenesis for limb and myocardial ischemia. Gene Ther. 2003;10(4):285-91. doi: 10.1038/sj.gt.3301969.

32. Patel JV, Abraheem A, Chackathayil J, Gunning M, Creamer J, Hughes EA, et al. Circulating biomarkers of angiogenesis as indicators of left ventricular systolic dysfunction amongst patients with coronary artery disease. J Intern Med. 2009;265(5):562-7. doi: 10.1111/j.1365-2796.2008.02057.x.

33. Hu S, Cao S, Tong Z, Liu J. FGF21 protects myocardial ischemia-reperfusion injury through reduction of miR-145mediated autophagy. Am J Transl Res. 2018;10(11):3677-88.

34. Deng Q, Hu B, Cao S, Song HN, Chen JL, Zhou Q. Improving the efficacy of therapeutic angiogenesis by UTMD-mediated Ang-1 gene delivery to the infarcted myocardium. Int J Mol Med. 2015;36(2):335-44. doi: 10.3892/ijmm.2015.2226.

35. Fiedler U, Reiss Y, Scharpfenecker M, Grunow V, Koidl S, Thurston G, et al. Angiopoietin-2 sensitizes endothelial cells to TNF-alpha and has a crucial role in the induction of inflammation. Nat Med. 2006;12(2):235-9. doi: 10.1038/ $\mathrm{nm} 1351$.

36. Qin Q, Qian J, Ma J, Ge L, Ge J. Relationship between thrombospondin-1, endostatin, angiopoietin-2, and 
coronary collateral development in patients with chronic total occlusion. Medicine (Baltimore). 2016;95(33):e4524. doi: $10.1097 / \mathrm{md} .0000000000004524$.

37. He L, Dang L, Zhou J, Bai J, Li YZ. Association of angiopoietin-1, angiopoietin-2 and caspase-5 polymorphisms with psoriasis vulgaris. Clin Exp Dermatol. 2015;40(5):556-63. doi: 10.1111/ced.12550.

38. Shiba M, Kato T, Funasako M, Nakane E, Miyamoto S, Izumi T, et al. Association between psoriasis vulgaris and coronary heart disease in a hospital-based population in Japan. PLoS One. 2016;11(2):e0149316. doi: 10.1371/ journal.pone.0149316.

39. Lin T, Wang L, Guo J, Liu P, Chen L, Wei M, et al. Association between serum LDL-C and ApoB and SYNTAX score in patients with stable coronary artery disease. Angiology. 2018;69(8):724-9. doi: 10.1177/0003319717748771.

40. Bodde MC, Hermans MPJ, Jukema JW, Schalij MJ, Lijfering WM, Rosendaal FR, et al. Apolipoproteins A1, B, and apoB/ apoA1 ratio are associated with first ST-segment elevation myocardial infarction but not with recurrent events during long-term follow-up. Clin Res Cardiol. 2019;108(5):520-38. doi: 10.1007/s00392-018-1381-5.

41. Shifman S, Bronstein M, Sternfeld M, PisantéShalom A, Lev-Lehman E, Weizman A, et al. A highly significant association between a COMT haplotype and schizophrenia. Am J Hum Genet. 2002;71(6):1296-302. doi: $10.1086 / 344514$.

42. Anuradha S, Mohan V, Gokulakrishnan K, Dixit M. Angiopoietin-2 levels in glucose intolerance, hypertension, and metabolic syndrome in Asian Indians (Chennai Urban Rural Epidemiology Study-74). Metabolism. 2010;59(6):774-9. doi: 10.1016/j.metabol.2009.09.022.

43. Gozal D, Khalyfa A, Qiao Z, Smith DL, Philby MF, Koren $\mathrm{D}$, et al. Angiopoietin-2 and soluble Tie-2 receptor plasma levels in children with obstructive sleep apnea and obesity. Obesity (Silver Spring). 2017;25(6):1083-90. doi: 10.1002/ oby.21859. 